Rabaska

Revue d'ethnologie de l'Amérique française

\title{
Henri Boily (1913-2008)
}

\section{Serge Gauthier}

Volume 6, 2008

URI : https://id.erudit.org/iderudit/019995ar

DOI : https://doi.org/10.7202/019995ar

Aller au sommaire du numéro

Éditeur(s)

Société québécoise d'ethnologie

ISSN

1703-7433 (imprimé)

1916-7350 (numérique)

Découvrir la revue

Citer ce document

Gauthier, S. (2008). Henri Boily (1913-2008). Rabaska, 6, 145-147.

https://doi.org/10.7202/019995ar

Ce document est protégé par la loi sur le droit d'auteur. L'utilisation des services d'Érudit (y compris la reproduction) est assujettie à sa politique d'utilisation que vous pouvez consulter en ligne.

https://apropos.erudit.org/fr/usagers/politique-dutilisation/
Cet article est diffusé et préservé par Érudit.

Érudit est un consortium interuniversitaire sans but lucratif composé de l'Université de Montréal, l'Université Laval et l'Université du Québec à Montréal. Il a pour mission la promotion et la valorisation de la recherche. https://www.erudit.org/fr/ 


\section{Henri Boily (1913-2008)}

Henri Boily, un digne descendant de la famille des ramancheurs Boily vient de mourir à Chicoutimi (Saguenay) en janvier 2008 et cela a ramené à ma mémoire bien des souvenirs ! Lors de notre première rencontre à Montréal en 1979, d'entrée de jeu, Henri Boily me précisa qu'il n'était pas lui-même ramancheur ! Il avait simplement été l'assistant de son père, un fameux ramancheur, durant de nombreuses années et de cela il s'était contenté. Tout de suite, Henri Boily insista pour dire que son père «n'était pas du tout comme le ramancheur Boily de Marius Barbeau ${ }^{1}$ !» Ainsi, selon Henri Boily, Barbeau était un bien respectable monsieur, mais ce qu'il racontait sur ses ancêtres ramancheurs n'était en quelque sorte que de l'humour. J'en convins très rapidement avec lui lorsqu'il me dit que son père, le ramancheur Thomas Boily (1873-1941), avait tout particulièrement fait carrière à Montréal après avoir quitté son Lac-Saint-Jean natal. Il avait eu pour clients des hommes d'affaires, souvent des Juifs pour qui son père étaient parfois « une sorte de Messie » selon ses dires, des sportifs, lutteurs et joueurs de hockey notamment, des membres de communautés religieuses, même des médecins parfois... presque tout le monde en fait et toutes classes sociales confondues. Nous étions alors bien loin de la traditionnelle clientèle d'agriculteurs des milieux ruraux ! Et, plus encore, Henri Boily me fit comprendre que le métier de son père était une technique qui n'avait rien de magique et relevait plutôt d'une longue tradition remontant même à Hippocrate, célèbre médecin grec, dont les procédés présentés dans ses traités antiques « des fractures » et « des articulations » n'étaient pas éloignés de ceux pratiqués dans sa famille, et tout particulièrement le fameux bandage d'éclisses en bois pour redresser et replacer les os défaits après le traitement. Selon Henri Boily, le ramancheur opérait surtout sur les entorses, les luxations, les fractures, laissant, comme l'écrit Louis Hémon dans Maria Chapdelaine à propos d'un de ses personnages qui est un ramancheur, « les maladies de l'intérieur du corps » à d'autres guérisseurs. Le taux de réussite semblait bon : les patients étaient toujours de plus en plus nombreux! Thomas Boily fit même breveter un liniment à son nom (« liniment rouge Boily») qui se vendit en pharmacie. Seules les poursuites incessantes du Collège des médecins devaient faire

1. Marius Barbeau, Le Saguenay légendaire, Montréal, Beauchemin, 1967, 145 p. 
cesser sa pratique de ramancheur à Montréal et l'inciter à retourner vivre au Lac-Saint-Jean. J'invite les lecteurs intéressés à en savoir plus sur les descriptions d'Henri Boily et sur la longue lignée des ramancheurs Boily du Québec ayant en fait plus de 300 ans d'histoire, à consulter le petit ouvrage paru récemment que j'ai consacré à cette pratique ${ }^{2}$.

Henri Boily est né à Saint-Jérôme (Lac-Saint-Jean), aujourd'hui Métabetchouan, le 12 juin 1913, fils de Thomas Boily, alors cultivateur, et d'Anna Belley. Il a fait des études classiques, devenant par la suite journaliste au poste de radio CKRs de Chicoutimi ${ }^{3}$. Il a œuvré de nombreuses années au Saguenay à titre de responsable en relations publiques toujours pour le poste CKRs. Par la suite, il a déménagé ses pénates à Montréal où il a travaillé au service des relations publiques du Canadien national d'où il venait tout juste de prendre sa retraite au moment de ma première rencontre avec lui en 1979. Par la suite, il est retourné vivre à Chicoutimi où il vient de mourir le 16 janvier 2008, à près de 95 ans. Grand intellectuel, il s'est intéressé à l'histoire et à la généalogie des familles Boily et Lavoie. Il s'est aussi amusé à collectionner un vaste répertoire de glanures et de citations d'auteurs littéraires de divers siècles. Voilà un informateur lettré qui éloigne de nous l'idée d'une histoire du folklore figée et en voie de disparition, mais plutôt démontre le cheminement d'un héritage patrimonial en constante évolution. Qu'on se le dise : il y a encore du terrain ethnologique à faire même de nos jours et pas seulement pour répéter ce qui a été dit!

Après le dépôt de mon mémoire, je me suis un peu éloigné de ce sujet pour privilégier par la suite une approche plus historienne qu'ethnologique dans mes recherches ${ }^{4}$. Je n'aurais sans doute jamais repensé à ce mémoire sur les ramancheurs Boily ${ }^{5}$, sans un appel téléphonique d'Henri Boily, un samedi soir de juillet 2006. Après avoir eu peine à reconnaître ce monsieur que je n'avais pas vu ni entendu depuis plus de 25 ans, ce dernier m'affirma qu'il souhaitait que je fasse paraître mon mémoire sous la forme d'un livre, ce que je fis finalement à sa suggestion en 2007. Entre-temps, j'ai rencontré à nouveau Henri Boily à Chicoutimi (désormais Saguenay) en août 2006 et quel plaisir ce fut de renouer avec cet informateur unique qui ne manqua pas à nouveau de m'étonner! Sans lui, aurais-je eu jamais l'intention de publier mon livre sur les ramancheurs Boily? Sans doute pas ! Et de cela je le remercie maintenant, comme aussi pour m'avoir fait comprendre que l'héritage

2. Serge Gauthier, Les Ramancheurs Boily au Québec. De Charlevoix au Saguenay et jusqu'à Montréal, La Malbaie, Éditions Charlevoix, 2007, 80 p.

3. Ces informations proviennent de notes biographiques compilées par le fils d'Henri Boily, maître Gratien Boily de Québec.

4. Voir à ce sujet mon ouvrage publié avec Normand Perron, Histoire de Charlevoix, Québec, Presses de l'Université Laval, 2000, 395 p.

5. Déposé en 1982 à l'École des Gradués de l’Université Laval. 
traditionnel des Boily est bien plus qu'une amusante dissertation littéraire à la sauce parfois trop touristique, mais surtout un long apprentissage qui n'en finit jamais de se transmettre pour qui consent les efforts requis.

En conclusion, vous me permettrez une dernière anecdote à peine croyable et pourtant vraie : au lancement de mon livre en juillet 2007 et auquel monsieur Boily n'a pu assister à cause de son grand âge, une femme dans la quarantaine de la famille Boily s'est présentée à moi - alors que je venais de dire et d'écrire que la lignée des Boily ramancheurs étaient désormais éteinte comme étant une ramancheuse pratiquant toujours le métier dans sa région ${ }^{6}$. La lignée n'est pas morte, venait-elle me dire ! J'ai bien reçu le message et monsieur Henri Boily le sait peut-être aussi là où il se trouve aujourd'hui : la tradition folklorique ne meurt jamais vraiment, même si elle échappe quelquefois aux ethnologues qui désirent parfois se l'approprier un peu personnellement et bien trop définitivement.

Serge Gauthier Centre de recherche sur l'histoire et le patrimoine de Charlevoix

\section{DERNIÈRE HEURE}

Au moment d'aller sous presse, nous apprenons le décès de notre collègue Conrad Laforte survenu le 4 septembre dernier à l'Hôpital général de Québec. Il avait 86 ans et il était membre honoraire de notre Société. On se souviendra que Rabaska a publié dans son premier volume (2003, p. 79-112) un portrait de l'ethnologue - avec notice biographique et bibliographie - fait par Jean-Pierre Pichette à partir d'une entrevue.

6. Que je n'identifie pas à sa demande à cause des poursuites possibles du Collège des médecins. 